\title{
Prolonged, unsignaled, inescapable shocks increase persistence in subsequent appetitive instrumental learning
}

\author{
JAW-SY CHEN and ABRAM AMSEL \\ University of Texas at Austin, Austin, Texas 78712
}

\begin{abstract}
In the first experiment, a prolonged period of intermittent, unsignaled shocks preceded appetitive runway acquisition, under either continuous (CRF) or partial reinforcement (PRF) and extinction. In the second experiment, the shock treatment came between CRF or PRF acquisition and extinction; and in the third experiment, the shocks intervened between appetitive CRF acquisition and shock-punishment extinction. The main finding was that compared with an unshocked control, shock facilitated acquisition in Experiment 1, and led to increased resistance to extinction and/or punishment in all experiments. In Experiment 1, the shock effect in appetitive extinction was seen mainly in the CRF group; in Experiment 2, the effect was to increase persistence in both the CRF and PRF groups; and in Experiment 3 , shock treatment produced stronger resistance to punished extinction. The discussion is in terms of habituation and a general theory of persistence, and the concept of helplessness.
\end{abstract}

According to a general theory of persistence (Amsel, 1972), behavioral habituation is an active process in which persistence is built by counterconditioning ongoing activity $\left(R_{O}\right)$ to the originally disruptive stimulus $\left(\mathrm{S}_{\mathrm{X}}\right)$. Repeated presentation of novel and/or noxious stimuli, conditioned or unconditioned, at first evoke responses $\left(\mathrm{R}_{\mathrm{X}}\right)$ that interfere with ongoing activity. The habituation of these responses, according to this view, involves counterconditioning of $R_{O}$ to $S_{X}$ which counterbalances the disruption of $S_{X}-R_{X}$. Other things equal, animals that have undergone prolonged habituation treatments should be more resistant to extinction, because such animals are then less susceptible to disruption by stimuli of the class $S_{X}$, of which feedback cues $\left(\mathrm{s}_{\mathrm{F}}\right)$ from anticipatory frustration $\left(\mathrm{r}_{\mathrm{F}}\right)$ and cues $\left(\mathrm{s}_{\mathrm{P}}\right)$ from conditioned fear $\left(r_{P}\right)$ can be regarded as members.

We report three experiments in which prolonged periods of inescapable electric shock preceded acquisition and/or extinction of an appetitive running response. In the first experiment, the habituation-toshock treatment preceded appetitive runway acquisition under either continuous (CRF) or partial reinforcement (PRF), which was then followed by extinction; in the second experiment, the shock treatment came between CRF or PRF acquisition and extinction; in the third, shock treatment was given after appetitive CRF acquisition, but, unlike

This work was supported by a grant (BMS74-19696) from the National Science Foundation. The technical assistance of Jim Davis is gratefully acknowledged. Requests for reprints should be sent to A. Amsel, Department of Psychology, University of Texas at Austin, Austin, Texas 78712. the first and second experiments, the extinction trials included shock punishments.

\section{EXPERIMENT 1}

There is already evidence from a variety of procedures that rats subjected to intense aversive stimulation are more resistant to extinction than controls; but these procedures are mainly "on the baseline," that is to say, the stimulation has been administered in the context of the behavior being investigated. For example, electric shock combined on some acquisition trials with food reward in the runway increases later resistance to extinction (Banks, 1967; Brown \& Wagner, 1964; Fallon, 1971; Terris \& Wechkin, 1967). Loud tones that disrupt barpressing have been shown to make fixed-ratio responding more resistant to extinction (Amsel, Glazer, Lakey, McCuller, \& Wong, 1973). Compared with nonshock controls, coerced approach to shock and even free shock in a runway enhance resistance to subsequent runway extinction (Wong, 1971). A number of unpublished experiments in our laboratory have suggested that rats exposed to electric shock "off the baseline," in a manner analogous to learned-helplessness treatments, seem more persistent than no-shock controls in the extinction of a continuously rewarded running response. Rosellini and Seligman (1975) have demonstrated that animals treated with inescapable shock are less able to escape from primary frustration. They have also provided some evidence that shock, whether inescapable or not, introduced during the period of appetitive runway training "marginally increased resistance to extinction"' (p. 152).

Our first experiment asked whether a period of 
shock treatment off the baseline, sufficiently prolonged to produce apparent habituation in both the shock and intershock intervals, affects the course of immediately following CRF or PRF acquisition and persistence as reflected in extinction.

\section{Method}

Subjects and Design. The subjects were 40 albino rats of the Holtzman strain bred in our laboratory. They were 60 to 65 days old at the beginning of the shock treatment phase (Phase 1). Each replication consisted of 10 rats, half of which receive: 1 a series of unsignaled electric shocks (SK) while another half (NS) did not. Sex and number of rats to receive CRF or $50 \%$ PRF treatments during Phase 2 runway training were balanced in each replication. The four replications comprised a 2 by 2 by 2 factorial design with shock condition (SK or NS) as the first factor, reward condition (CRF or PRF) as the second, and sex as the third, with five rats in each group.

Apparatus. Ten identical Plexiglas cages $(22 \times 13 \times 19 \mathrm{~cm})$ were separately housed in sound-attenuated, ventilated wooden boxes $(33 \times 31 \times 33 \mathrm{~cm})$ with a $6-\mathrm{W}$ light at the ceiling. The cage floor was stainless steel rods $(1.6 \mathrm{~mm}$ in diameter $)$ spaced $1.1 \mathrm{~cm}$ apart. Five of the cages had their grid floors wired to the scrambled output of a shock generator (Grason-Stadler, Model 700) through a series of current-limiting resistors which provided a constant current of $1 \mathrm{~mA}$ for each cage independent of the activity of the rats during shock. The shock durations were controlled by a timer. The intershock intervals and number of shocks were controlled by a tape reader and a predetermining counter, respectively.

The runway, covered with transparent Plexiglas, consisted of a $27-\mathrm{cm}$ startbox, a $67-\mathrm{cm}$ alley, and a $34-\mathrm{cm}$ goalbox. All were $7.6 \mathrm{~cm}$ wide and $8 \mathrm{~cm}$ high. The grid floor of the runway was stainless steel rods, $1.6 \mathrm{~mm}$ in diameter and spaced at $.8 \mathrm{~cm}$ apart. The start door was opaque Plexiglas. A metal door served to prevent retraces from the goal region. The food cup, $13 \mathrm{~cm}$ from the last photobeam, was a semicircle of sheet metal extending the total width of the goalbox and was mounted on the end wall of the goalbox. The lip of the cup was $2 \mathrm{~cm}$ above the floor and its depth was $1.3 \mathrm{~cm}$. The three $31-\mathrm{cm}$ segments of the alley yielded start, run, and goal times recorded on Standard Electric timers controlled by the activation of a microswitch on the startdoor and the interruption of three photobeams.

Procedure. The rats were not handled prior to or during shock or control treatment, which began $4 \mathrm{~h}$ after they were housed in the appropriate cages. Rats in the shock group were exposed to 72 unsignaled shocks over a 12-h period on each of 6 successive days, while the controls remained undisturbed. The footshocks were administered on a VI 10-min schedule with a range of 5 to $15 \mathrm{~min}$ and at a shock intensity of $1 \mathrm{~mA}$. The shock durations increased from 1 to $5 \mathrm{sec}$ at $1-\mathrm{sec}$ increment every day and stayed at $5 \mathrm{sec}$ on Days 5 and 6 . The rats were fed 10-g Purina Lab Chow during the shock-free periods in the interval between $2 \mathrm{~h}$ following and $2 \mathrm{~h}$ preceding shock treatment. Water was always available.

Six hours after the 6-day shock treatment, the rats were moved into individual holding cages in the experimental room and then returned to their home cages after the experimental session. The test phases of the experiment, conducted in the runway, were an 8-day acquisition and a 6-day extinction period at six trials a day. Half of the shocked rats and half of the controls were trained on a CRF, half on a $50 \%$ PRF schedule. The PRF schedule consisted of three rewarded and three nonrewarded trials each day according to the following sequences: RNRNNR, NRNNRR, NRRRNN, RNNRNR, RRNNRN, NNRRNR, NRNRRN, RNNNRR.

Ten minutes before each day's training, the rats were moved from their home cages into the experimental room and placed into individual holding cages. On each trial, the rat was removed from the holding cage and placed in the startbox. After $3 \mathrm{sec}$, the start door was raised and then lowered as soon as the rat left the startbox. On goalbox entry, the goal door was lowered to prevent retracing. Running order was randomized from day to day and among CRF and PRF subjects. The ITI was about 12-15 min. The reward was one $500-\mathrm{mg}$ Noyes food pellet. On rewarded trials, the rat remained in the goalbox until the food was consumed. On nonrewarded or extinction trials, it was left in the goalbox for $30 \mathrm{sec}$. During extinction, the rat was removed from the runway and placed in the goalbox for $30 \mathrm{sec}$ if it took longer than $60 \mathrm{sec}$ to traverse any $31-\mathrm{cm}$ segment, and a $60-\mathrm{sec}$ score was recorded for that and subsequent measures. The rats were returned to their home cages and fed about $30 \mathrm{~min}$ after the last trial of a day. The amount of food provided each day, including amounts given as reward, was $10 \mathrm{~g}$.

\section{Results and Discussion}

Shock treatment (Phase 1). The first few brief shocks produced rapid and vigorous movement, the emission of trains of short but sharp sounds, urination and defecation, hair erection, and irregular breathing. Many of these signs of intense reaction to shock persisted into the intershock interval for several seconds and even minutes. As shock trials progressed, even though shock durations was increased over days, the vigorous overt reactions to shock eventually disappeared. During the first $2 \mathrm{~h}$ of shock, the number of fecal boli decreased from a mean of 5.9 on Day 1 to 1.2 on Day 6 in the shocked group, while defecation of the control group remained at about the same level with means of 1.2 on Day 1 and 1.0 on Day 6. These results are supported by a significant shock effect, $F(1,32)=50.06, p<$ .001 , and a significant Shock by Block interaction, $\mathrm{F}(1,32)=51.12, \mathrm{p}<.001$. After several sessions of shock, termination of shock was followed by a return to "normal" resting behavior more and more quickly. At the end of the shock-treatment period, the shocked rats were much easier to handle than the controls.

These observations are reasonably good evidence of behavioral habituation to repeated intense electric shock. There are, however, important differences between our shock treatment and the usual habituation experiment. First of all, our disruptive stimulus was more intense than the usual habituation stimulus. Second, the duration of shock was gradually increased from day to day. Third, a large number of electric shocks were applied over a 6-day period with a relatively long intertrial interval, i.e., on a VI 10-min schedule. We call attention to the temporal factor in particular because it provides an opportunity for the disruptive reaction to shock to subside and for a return to an appearance of normalcy between trials.

In general persistence terms, there are two sources of disruptive stimulation $\left(\mathrm{S}_{X}\right)$ in the shock situation: (a) stimulation arising out of the shock itself $\left(S_{P}\right)$ and (b) the stimuli arising from the anticipation of shock $\left(s_{P}\right)$. During early shock treatment, both disruptive stimuli interfere with normal ongoing behavior $\left(R_{O}\right)$ : the rat reacts vigorously to shock and is immobile 
between shocks. But with repeated shocks, counterconditioning of $R_{O}$ to $S_{X}$ develops, particularly to the weaker $s_{P}$. Consequently, ongoing behavior returns to normal, particularly between shocks. The rat displays reduced disruption to anticipated shock, and to some extent to shock itself. A striking indicant of the habituation to shock and its presumed transfer to other $S_{X} s$ was the relative ease with which the shocked rats could be handled when taken out of the shock cages after treatment.

Runway acquisition (Phase 2). Analyses of variance were applied to speed scores and retraces. These analyses consisted of three between-groups variables, shock, reward, and sex, and two within-group variables, blocks of trials and trials within blocks. In both this and the second experiment there was a main effect of sex in extinction, suggesting that males ran faster and retraced less than females. However, there was no significant interaction involving the sex factor, and there is no further need to refer to this variable in the analyses that follow.

The left side of Figure 1 shows the results for start, run, and goal speeds during runway acquisition. The interaction of shock and block was significant only in the start measure, $F(7,224)=3.06, p<.001$; the shocked rats started faster than controls early in training, while both reached about the same asymptotic speeds on Day $8(\mathrm{p}>.05)$. The reward effect was significant in the goal measure, $F(1,32)=12.79$, $\mathrm{p}<.005$, indicating lower goal speeds in the PRF condition. The Reward by Block interactions were significant for run and goal measures, Fs $(7,224)=$ 2.88 and 2.49, ps $<.01$ and .05; PRF groups were faster in the run section but slower at the goal, reflecting the partial reinforcement acquisition effect (PRAE) (Goodrich, 1959; Haggard, 1959). Finally, although the CRF-PRF acquisition differences seemed smaller in the start and run measures but greater at the goal for shocked rats (SK-CRF and SKPRF) than for controls (NS-CRF and NS-PRF), neither the interaction of shock and reward nor of shock, reward, and block was significant in any measure.

Retrace data are a sensitive indicator of behavioral disruption (Amsel \& Chen, 1976). A retrace is an occasion on which the rat makes a 180-deg turn and moves in the direction opposite to the goal in the runway. The left portion of Figure 2 presents retrace data for acquisition. Shocked rats retraced less in acquisition than NS controls and stopped retracing on Day 4, while NS groups retraced until Day 7. These observations were supported statistically by a significant shock effect, $F(1,32)=4.21, p<.05$, and a significant interaction of shock and block, $F(7,224)=2.46, p<.025$.

Runway extinction (Phase 3). All rats extinguished and, for every comparison within shocked and within nonshocked group for every measure, there was a highly significant partial reinforcement extinction effect (PREE), both in terms of main effects of reward and interactions of reward and block of trials. These data are shown on the right side of Figure 1. A significant shock effect, $F(1,32)=$

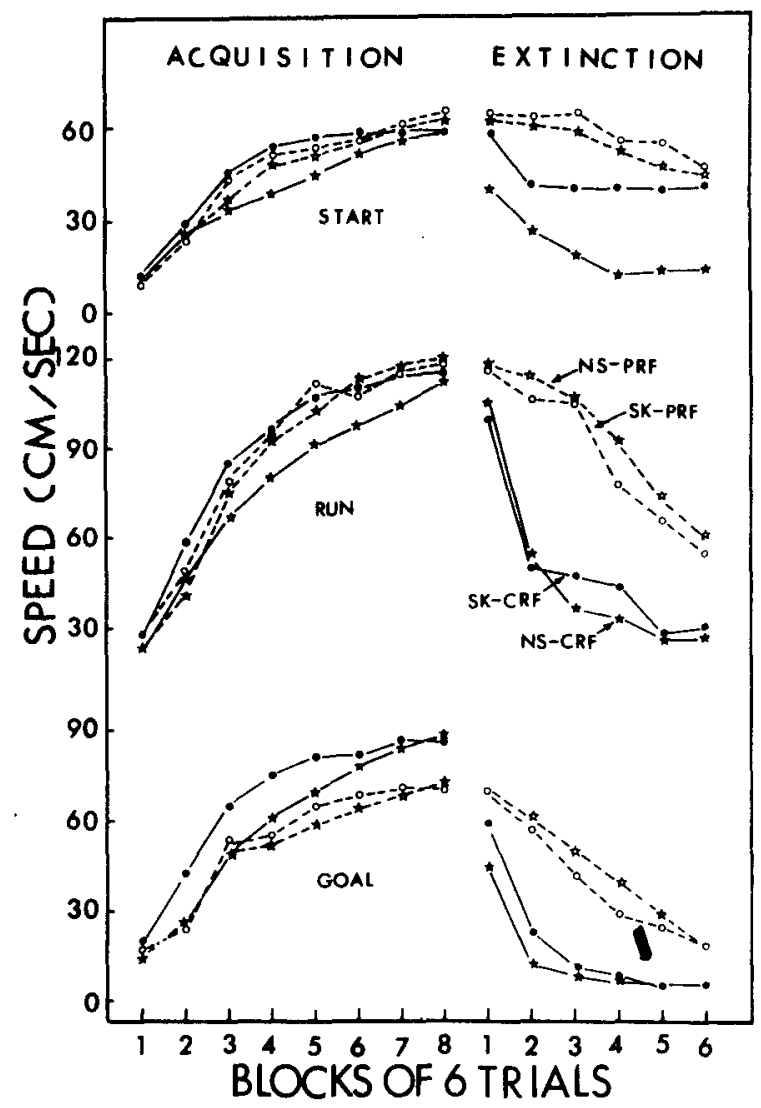

Figure 1. Acquisition and extinction speed data for Experiment 1. (Abbreviations: $\mathbf{S K}=$ shock, $\mathbf{N S}=$ no shock, $\mathrm{CRF}$ $=$ continuous reward, PRF $=$ partial reward.)

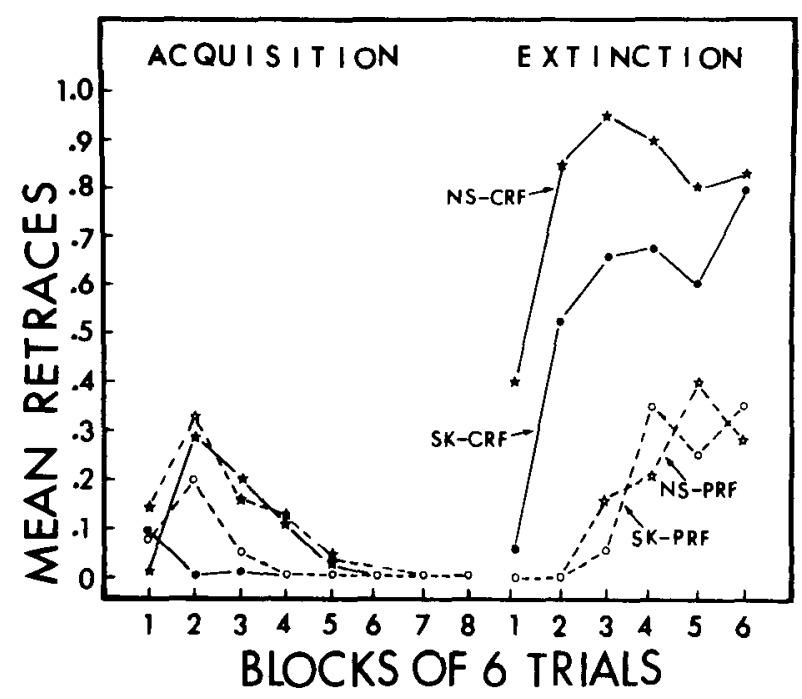

Figure 2. Acquisition and extinction retrace data for Experiment 1. 
$13.68, \mathrm{p}<.001$, in the start measure indicated that rats exposed to repeated electric shock started faster and were more resistant to extinction than nonshock controls. A significant Shock by Reward interaction for the start measure, $F(1,32)=7.56, p<.01$, reflected an overall reduction in the size of PREE in shocked groups, which was attributable to the faster starting of SK-CRF rats compared to their nonshock (NS-CRF) counterparts, $F(1,16)=22.82, p<.001$. The difference between the corresponding PRF groups was not significant.

Figure 3 represents the start speeds for the terminal acquisition day and for all extinction days on a trial-by-trial basis for all groups. Separate analyses of variance performed on the acquisitionextinction transition confirm significant interactions of shock and block, $F(1,32)=11.45, p<.005$, and Shock by Reward by Block, $F(1,32)=6.38$, $p<$ .025 . It is particularly striking to examine the first block of extinction trials, where a sharp decrement from asymptotic speed is evident in the NS groups, and particularly in Group NS-CRF. Speeds for SK groups actually rise on this first day of extinction training. Further analyses of the simple main effect of shock and the interactions of shock and trial support the observations that SK groups were faster to start than NS controls and had significantly flatter extinction slopes across trials within blocks. Analyses from Days 1 through 6 for shock: $F s(1,32)=10.12$, $4.25,8.43,13.71,14.35$, and 8.42 , ps $<.005,<.05$, $<.01,<.001,<.001$, and $<.01$. The Shock by Trial interactions were significant for Days 3 and 4 , $\mathrm{Fs}(5,160)=2.65$ and 2.40 , ps $<.025$ and $<.05$. More importantly, the Shock by Reward by Trial interaction was significant, indicating that the sharpest drop for NS-CRF occurred on Days 2, 3, and 4, Fs $(5,160)$ $=5.10,2.51$, and 2.34 , ps $<.001,<.05$, and $<.05$.

Finally, retrace data, shown in the right panel of Figure 2, reflect a clear PREE pattern-a significant reward effect, $F(1,32)=53.63, p<.001$, and a significant interaction of reward and block, $F(5,160)$ $=3.02, \mathrm{p}<.01$. The CRF groups retraced more than the PRF, and increased retracing faster over extinction. Although the overall comparison between shocked and nonshocked groups was not significant, SK-CRF rats made fewer retraces than NS-CRF, $F(1,16)=5.40, p<.05$.

The general patterns of runway acquisition and extinction are consistent with several previous unpublished observations. Acquisition of an appetitively reinforced running response was not suppressed or disrupted by prior exposure to repeated unsignaled, inescapable electric shocks; in fact, the shocked rats retraced less and ran faster than the nonshocked in the early stage of learning. In extinction, although shock treatment did not produce persistence differences in the already persistent PRF groups, the SKCRF rats were more persistent in initiating approach

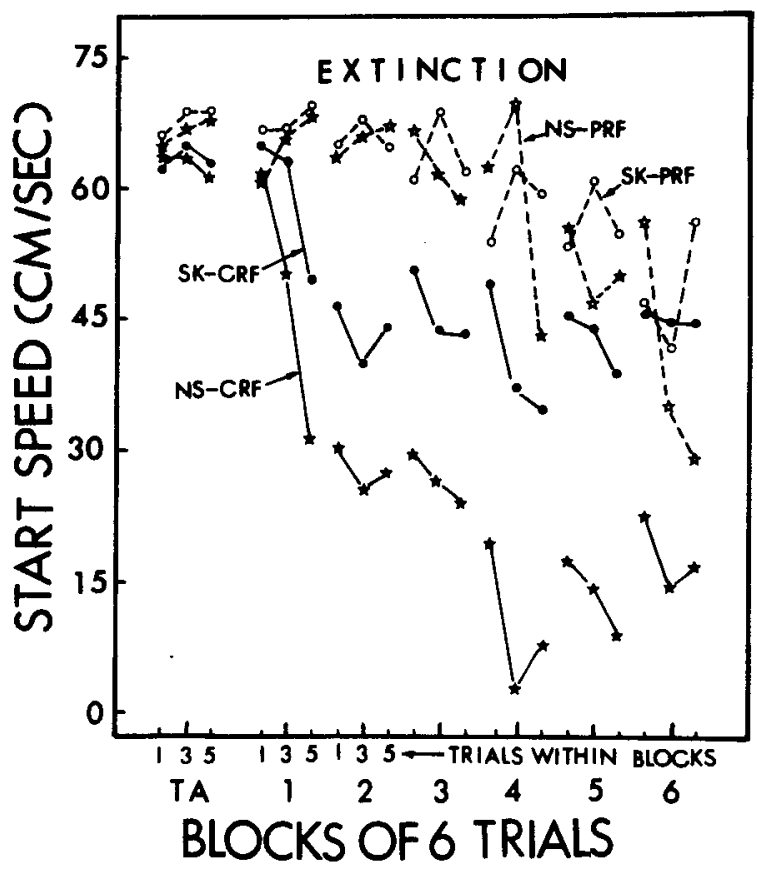

Figure 3. Mean speed in start measure for the terminal acquisition (TA) and extinction days on a trial-by-trial basis.

and in failure to retrace than the NS-CRF controls. Furthermore, there were clear within-session differences in extinction pattern between SK-CRF and NS-CRF: the latter showed sharp decrements in speed from trial to trial, while the former showed slower extinction even within days.

\section{EXPERIMENT 2}

Experiment 1 demonstrated that prior shock treatment enhances performance on early trials of a foodreinforced running response and increases resistance to extinction for CRF but not for PRF animals. In the second experiment, we interposed the electric shock treatment between the acquisition and extinction phases of runway training so that we could determine whether the shock treatment had a direct effect on subsequent resistance to extinction, uninfluenced by the interaction of shock and reinforcement schedule in acquisition.

\section{Method}

Subjects and Design. The subjects were 40 experimentally naive albino rats of the Holtzman strain bred in our laboratory. They were 43 days old at the beginning of the experiment, and they were about the same age as those of Experiment 1 during shock treatment phase. Experiment 2 consisted of three phases-runway acquisition, shock treatment, and runway extinction, in that order-comprising a 2 by 2 by 2 factorial design with reward condition (CRF or PRF), shock condition (SK or NS), and sex as the factors.

Apparatus and Procedure. The apparatus was the same as in Experiment 1. The rats received no handling in their home cages during the 6-day deprivation period that began at 43 days of age. Phase 1 runway acquisition consisted of a 4-day training, a 6-day 
rest period in home cage, and then a second 4-day training. The 6-day rest interval was introduced so that subjects would have the same 6-day shock treatment period between terminal acquisition and extinction. Otherwise, the procedure was identical to Phase 2 runway acquisition in Experiment 1. The 6-day shock treatment that followed runway acquisition in this experiment was identical to that employed in Experiment 1. The Phase 3 extinction period was 7 days, and the same extinction criterion was applied as in Experiment 1.

\section{Results}

Runway acquisition (Phase 1). Since the data from the start and run measures were similar, we show, in Figures 4 and 5, respectively, only start and goal speeds during runway acquisition and extinction. The block effect was significant in all measures (ps $<.001$ ), reflesting appetitive instrumental learning in both groups. The reward effect was significant only in the goal measure, $F(1,32)=20.54, p<.001$, reflecting faster approach to the goal under $C R F$ than under PRF conditions. The Reward by Block interactions were significant for run and goal, $\mathrm{Fs}(7,224)=6.85$ and 2.05 , ps $<.001$ and $<.05$; the PRF group ran faster in the run segment (not shown in graph) but more slowly in the goal segment than the CRF group in the later stages of acquisition, again reflecting the PRAE. The 6-day period between Days 4 and 5 of acquisition training had little, if any, effect on the learning curve. The CRF group was at a higher asymptote than the PRF group in the goal measure, $F(1,32)=14.84, p<.001$; however, neither the main effect of trials nor the interaction of any other variable with trials was significant $(p>.05)$, indicating that all groups reached asymptotic speeds by the end of acquisition.

Shock treatment (Phase 2). Although we had no adequate basis of differentiating between PRF and CRF animals in terms of their habituation to re-

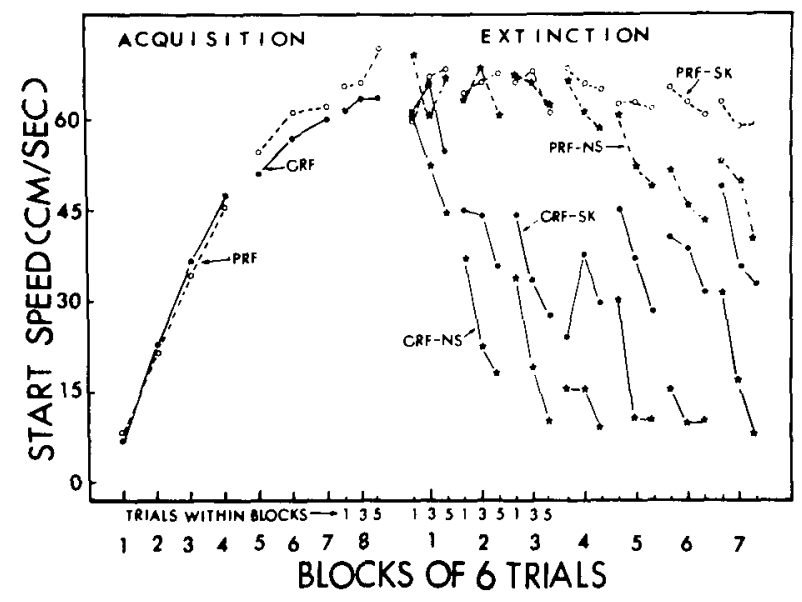

Figure 4. Acquisition and extinction curves for the start measure in Experiment 2. The terminal acquisition and all extinction data are plotted on a trial-by-trial basis. (Abbreviations: $\mathrm{CRF}=$ continuous reward, $P R F=$ partial reward, $S K=$ shock, NS $=$ no shock.)

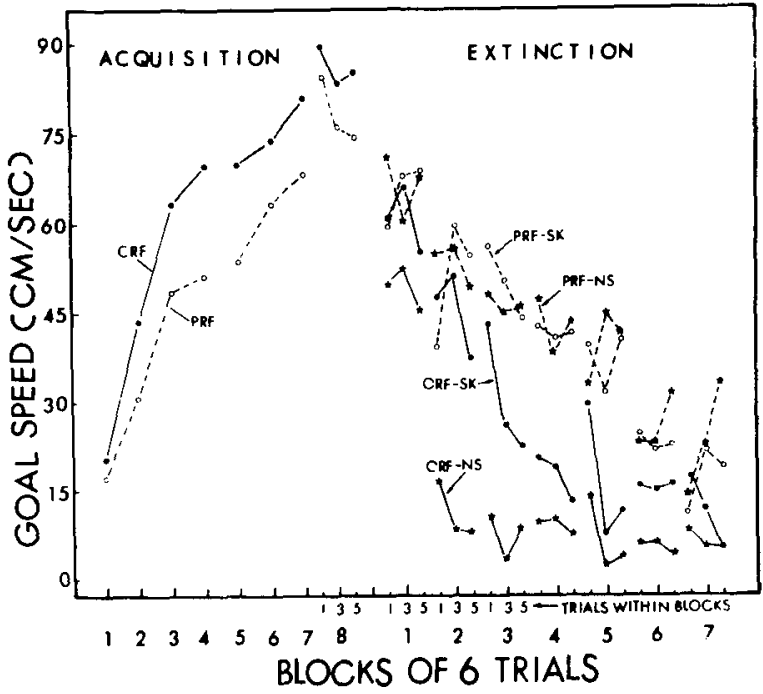

Figure 5. Acquisition and extinction curves for the goal measure in Experiment 2. The terminal acquisition and all extinction data are plotted on a trial-by-trial basis.

peated electric shock, in general, the rats subjected to shock showed the same pattern of behavioral habituation as in Experiment 1.

Runway extinction (Phase 3). It is clear from Figures 4 and 5 that, although the shock treatment did not eliminate the PREE, it did have an effect on extinction in both the PRF and CRF groups. Significant reward effects, $F s(1,32)=123.93,41.80$, and 14.60 , ps $<.001$ for all measures, and significant Reward by Block interactions, Fs $(6,192)=9.67$, 11.92 , and 6.38 , ps $<.001$ for all measures, reflect the presence of the PREE despite the 6-day period of repeated electric shocks interpolated between acquisition and extinction. A significant shock effect in the start segment, $F(1,32)=20.56, p<.001$, and Shock by Block interaction in the start and goal, $\mathrm{Fs}(6,196)=2.32$, and 3.09 , and $\mathrm{ps}<.05$ and $<.005$, respectively, indicate that the shocked rats were more resistant to extinction than the nonshock controls. Separate analyses of variance indicate that the combined nonshock groups (CRF-NS and PRF-NS) had a greater loss of response speed than did the shocked groups (CRF-SK and PRF-SK) from terminal acquisition to the first day of extinction, $F s(1,32)=5.17$ and 5.20 , ps $<.05$, for the start and goal speeds. Nonshock groups were less persistent in terms of start speed than were the shocked groups on each of the subsequent 6 extinction days, $\operatorname{Fs}(1,32)=4.09,4.62,5.50,12.72,23.18$, and 13.52, ps $<.05,<.05,<.025,<.001,<.001$, and $<.001$ for Days 2 through 7 . The nonshocked groups were significantly less persistent also at the goal, $F s(1,32)=4.72$ and 4.15 , ps $<.05$, for Days 2 and 3.

The interactions of shock and reward, $F(1,32)$ $=4.17, p<.05$, and shock, reward, and block, 
$F(6,192)=2.15, p<.05$, were significant in the start measure, reflecting the fact that there was a PREE in each of the shock and nonshock conditions, but that the PREE was smaller after the shock treatment. The simple main effect of shock was significant in the CRF comparison, $F s(1,32)=19.96$ and 4.47 , ps $<.001$, and $<.05$ for start and goal measures, but not in the PRF comparison, although the differences were in the same direction. The rate of extinction was slower for shock than for nonshock groups both across blocks and across trials within blocks, the curves diverging across blocks and across trials within blocks in the CRF groups, Fs $(6,192)$ $=2.32$ and 3.60 , ps $<.05$ and $<.005$ for the start and goal measures, respectively, and also in the PRF groups, $F(6,192)=3.06, p<.01$, for the start measure.

The retrace data over acquisition and extinction are shown in Figure 6. With this indicant, a clear PREE pattern also emerges: the significant reward effect, $F(1,32)=39.41, p<.001$, and interaction of reward and block, $F(6,192)=3.11, p<.005$, confirm that the CRF groups retraced more and increased their retracing over extinction faster than the PRF groups. More important, the overall comparison between shocked and nonshocked groups was also significant, $F(1,32)=8.37, p<.01$.

There seems little question that a prolonged shock treatment applied after runway acquisition training but before extinction has a sizable effect on rate of extinction. The shock treatment applied in this manner increased persistence after CRF training, as in Experiment 1; it also increased persistence after PRF training, unlike Experiment 1.

\section{EXPERIMENT 3}

Shock treatment produced faster running early in acquisition in Experiment 1 and led to increased resistance to extinction in Experiments 1 and 2. In the first two experiments, we looked for a transfer of the shock effect to appetitive learning and extinction; in the third experiment, we wanted to evaluate two separate aspects of the shock effecthabituation to shock and habituation to anticipation of shock. Therefore, we started all animals on CRF runway training and, as in Experiment 2, half the subjects received a 6 -day period of shock treatment but the other half did not. Finally, unlike Experiment 2, the test phase was shock-punishment extinction. If, as we assume, behavioral habituation in the repeated-shock situation involves counterconditioning to ongoing behavior of shock and anticipation of shock, then the shocked rats should be more resistant to punished extinction, despite the mediation of runway extinction by anticipatory frustration and the anticipation of shock (fear). The

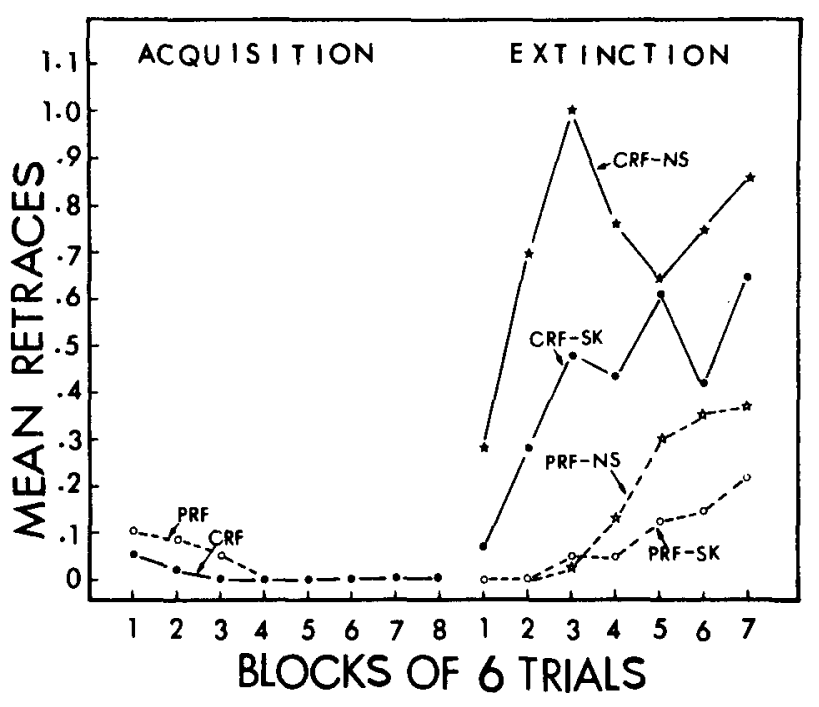

Figure 6. Acquisition and extinction retrace data for Experiment 2.

shocked rats should also display less disruption and less "emotion" than the controls after shock in the goalbox.

\section{Method}

Subjects and Design. The subjects were 20 albino rats, 10 males and 10 females, of the Holtzman strain bred in our laboratory. They were 49 days old at the beginning of the experiment, and so they were about the same age as the rats in Experiments 1 and 2 during the shock-treatment phase. In two replications of 10 each, all rats were subjected to CRF runway training in the first phase. In the second phase, half of the rats, equally divided between male and female, received shock treatment while the other half stayed in identical control boxes undisturbed. The test phase was extinction plus shock punishment at the end of the goal box.

Apparatus and Procedure. The shock boxes and procedure for shock-habituation were the same as in Experiment 2. The rats were not handled in their home cages during the 6-day deprivation period that began at 49 days of age. Phase 1 runway acquisition consisted of 8 days of CRF training for all subjects. The reward was one $500-\mathrm{mg}$ Noyes food pellet. The Phase 2 shock treatment was administered in a 6-day period. In Phase 3, footshocks were delivered through the scrambled output of a shock generator (Grason-Stadler, Model 7000), starting when the animal interrupted the last photobeam $8 \mathrm{~cm}$ from the end of the goalbox. The shock intensity was $1 \mathrm{~mA}$ and the duration was $0.5 \mathrm{sec}$. Phase 3 lasted for 2 days at four trials a day. The ITI was about $15 \mathrm{~min}$. When the rat met the $60-\mathrm{sec}$ extinction criterion in any segment of the runway, it was placed in the goalbox and given the shock 5 sec later.

\section{Results}

Runway acquisition (Phase 1). The left side of Figure 7 shows the results for start, run, and goal speeds during runway acquisition. Analysis of variance was applied to speed data with shock treatment, block of trials, and trials within blocks as factors. The block effects were, of course, highly significant in all measures, reflecting appetitive learning in all subjects. Although shock group and nonshock control received identical treatment in this phase, the con- 


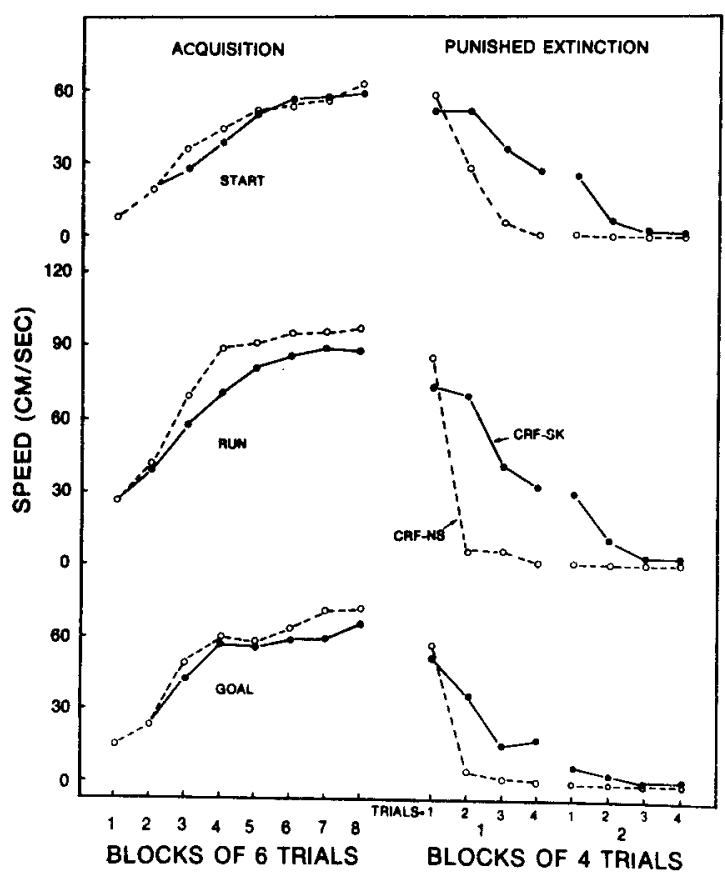

Figure 7. Acquisition and punished extinction speed data for Experiment 3. (Abbreviations: $\mathbf{C R F}=$ continuous reward, $\mathrm{SK}=$ shock, NS = no shock).

trols tended to run faster than the shocked rats in the run segment, $F(1,18)=6.49, p<.05$, but not in the others.

Shock treatment (Phase 2). The rats subjected to repeated electric shocks showed the same general pattern of behavioral habituation we observed in the first two experiments.

Punished extinction (Phase 3). Analyses of variance consisted of one between-groups variable, shock or no-shock, and one within-group variable, trials. Despite their higher running speed in one measure in acquisition, the control group extinguished more quickly than the shocked group in all measures, both in terms of the main effect, $\operatorname{Fs}(1,18)=7.14,11.32$, and 7.46 , ps $<.01$, for start, run and goal, respectively, and in terms of rate of extinction Fs $(7,126)$ $=4.50,10.29$, and 4.71, ps $<.001$ for all measures.

Consistent with the speed data, an analysis in terms of number of subjects reaching the criterion of extinction (Figure 8) showed that, while all subjects appeared to avoid the goal segment first, then the run and start segments, the control group was almost totally suppressed after the second trial, while the previously shocked group kept moving slowly. An analysis of variance yielded significant effects of shock, $F s(1,18)=18.89,25.60$, and 28.54 , ps $<.001$, for the start, run, and goal measures.

We now turn to the question, are there any differences in emotional and disruptive behavior to shock between the shock group and the no-shock control? It was very clear that the controls taking shock for the first time were difficult to remove from the goalbox. They urinated, defecated, squealed, and were difficult to handle. In contrast, the rats previously exposed to repeated shocks were tame and there was no sign of the emotional behavior shown by the controls.

\section{DISCUSSION}

The major findings in the first two experiments were (a) that shock habituation increased the rate of acquisition in Experiment 1, (b) that the shock treatment had a significant effect on extinction after CRF in both experiments and on extinction after PRF in Experiment 2, and (c) that the effects showed up mainly in the start segment in Experiment 1 but extended to the goal segment in Experiment 2. This suggests that when the shock treatment preceded acquisition, its effect was absorbed during PRF (but

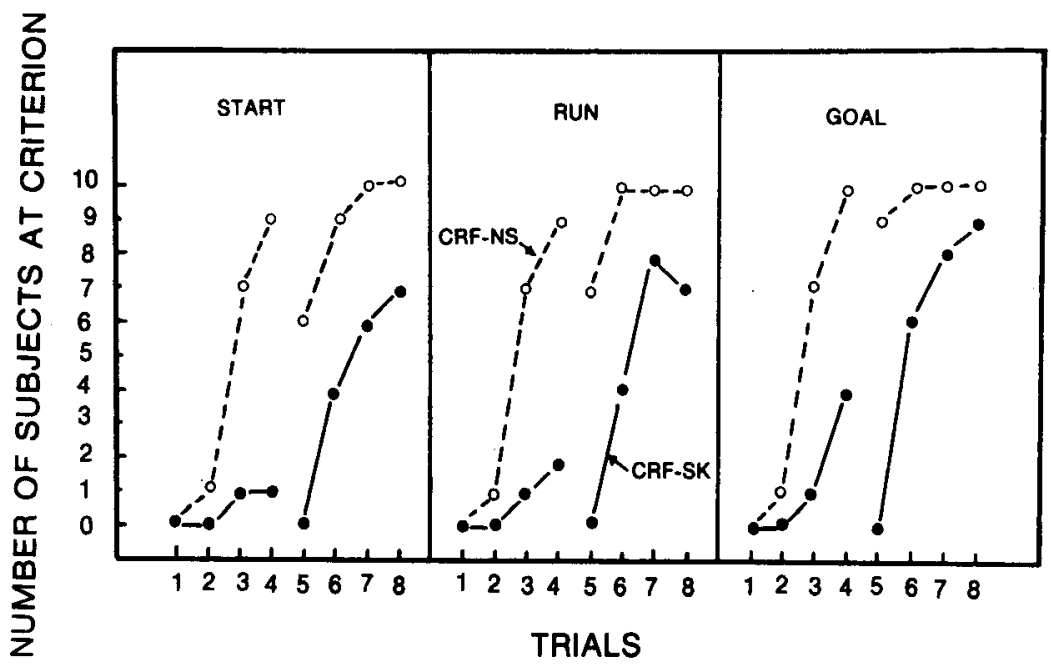

Figure 8. Number of subjects at 60 -sec extinction criterion $(n=10)$. 
not CRF) training, and that when shock was interpolated between acquisition and extinction, its effect carried over to affect both PRF and CRF extinction.

On the basis of a general counterconditioning view of persistence (Amsel, 1972), the faster running of the shocked groups early in acquisition and faster starting of Group SK-CRF in extinction in Experiment 1 can be taken to reflect the transfer of $S_{X}-R_{O}$ counterconditioning (habituation) from shock treatment to runway training: goal-directed approach is protected from the disruptive effects of novel runway stimuli and from the cues from anticipatory frustration $\left(r_{F}-S_{F}\right)$ in the PRF groups in acquisition, and from the $\mathrm{S}_{\mathrm{F}}$ cues, particularly in CRF subjects, in extinction. In Experiment 2, shock treatment interpolated between acquisition and extinction increases general persistence, the effects of which transfer to extinction following both CRF and PRF acquisition. In Experiment 1, where the shock effect was partly absorbed by the acquisition treatment, its effect on persistence in extinction was clearest in the start measure, where the intensity of $\mathrm{s}_{\mathrm{F}}$ was presumably weakest. Here the addition of weak general persistence transferring from the shock treatment would in terms of Weber's law, be most appreciable. On the other hand, at the goal, where $s_{F}$ intensity was great, the effect of a weak general persistence increment would be more difficult to measure. The effects of shock treatment in Experiment 2, unabsorbed by interpolated acquisition, would be strong in extinction and, consequently, have an additive effect on general persistence whether $\mathrm{s}_{\mathrm{F}}$ was weak (at the start) or strong (at the goal).

In Experiment 3, the previously shocked rats ran faster in punished extinction and exhibited much less reaction to shock in the goalbox than the controls, a result that also supports a general counterconditioning view of persistence. If the shock treatment makes the rat less susceptible to the disruptive effects of anticipated frustration, it should certainly attenuate the disruptive effects of conditioned fear $\left(s_{p}\right)$ in the alley. And, if this transfer from the shock chambers to the alley occurs, there should, of course, be transfer of the attenuated reaction to shock itself which, as we reported, is very apparent in the goalbox of the runway.

Our analysis has been in terms of habituation or counterconditioning to both the conditioned and unconditioned effects of shock, and it has a number of important implications. First of all, it illustrates that, while we are dealing in Experiment 3 with a simpler transituational transfer from fear-to-fear and shock-to-shock habituation effects, the mechanism in the first two experiments is a form of transfer from habituation of fear to attenuated anticipatory frustration effects in extinction, in keeping with the presumed similarity of fear to anticipatory frustration (Wagner, 1966). Secondly, our analysis in terms of behavioral habituation can explain the apparently contradictory findings that inescapable preshock can produce persistence in punished extinction (our results) or desistence in punished extinction (Anderson, Cole, \& McVaugh, 1968). According to this view, our procedure produces persistence because the shock experience, many shocks with graded increases in duration over a 6-day period, produces behavioral habituation, both of anticipated shock and unconditioned shock. The Anderson et al. experiment employed only nine shocks over a 30 -min span, presumably insufficient to produce habituation and persistence, but perhaps enough to produce sensitization to shock and, consequently, desistence. Thirdly, our finding that the previously shocked rat is less emotionally reactive to shock agrees with the observation that the inescapably shocked rat appears inactive to shock (Weiss, Glazer, \& Pohorecky, 1976) and shows less shockinduced aggression (Maier, Anderson, \& Lieberman, 1972). Put another way, we emphasize the distinction between the direct reaction (UCR) to electric shock as a UCS and the persistence and desistence of responding to nonreward and to punishment that reflects an instrumental "coping" reaction to cues from anticipatory frustration and fear.

Our experiments were not designed to test the learned helplessness hypothesis, so that they do not involve the "triadic" design of most of those studies. We feel, however, that we would be remiss not to try to relate our results to the learned helplessness hypothesis (e.g., Maier, Seligman, \& Solomon, 1969; Seligman, Maier, \& Solomon, 1971). If the rat learns, during a series of prolonged sessions of aperiodically presented electric shocks, that its responding can in no way prevent or affect the aversive consequences (Maier \& Seligman, 1976), then why should the animal that has presumably learned this "noncontingency" show more rapid acquisition of the foodrewarded response than its nonshocked control? Further, since the learned helplessness hypothesis postulates that reduction in motivation is an important consequence of inescapable shock (Maier \& Seligman, 1976), why should the shocked rats initiate the running response faster both in acquisition and extinction than nonshocked controls? Our findings offer the same difficulties for a learnedinactivity hypothesis (Glazer \& Weiss, 1976a, 1976b; Weiss, Glazer, \& Pohorecky, 1976) if such a hypothesis is applied more generally than to shock escape-avoidance. The inactive rat should be slower early in appetitive training, particularly if the novelty of the runway is at all aversive, and it should be less resistant to nonreward extinction, and particularly to punished extinction, than its unshocked counterpart.

We have previously suggested informally (see 
Rosellini \& Seligman, 1975, Note 1) that helplessness and persistence may be related in that both involve escape-avoidance deficits. But this is simply a descriptive treatment of the problem. It seems clear that any successful account of the effects of inescapable shock will have to go beyond escape-from-shock tests and will have to provide more tied-down explanatory mechanisms than are currently available.

\section{REFERENCES}

AMSEl, A. Behavioral habituation, counterconditioning, and a general theory of persistence. In A. H. Black \& W. F. Prokasy (Eds.), Classical conditioning II: Current research and theory. New York: Appleton-Century-Crofts, 1972.

AMSEL, A., \& CHEN, J. S. Ontogeny of persistence: Immediate and long-term persistence in rats varying in training age between 17 and 65 days. Journal of Comparative and Physiological Psychologv. 1976, 90. 808-820.

Amsel, A. Glazer. H., Lakey, J. R., McCuller, T., \& Wong, $P$. T. P. Introduction of acoustic stimulation during acquisition and resistance to extinction in the normal and hippocampally damaged rat. Journal of Comparative and Physiological Psychology, 1973, 84, 170-186.

Anderson, D. C.. Cole, J., \& McVaugh, W. Variations in unsignalled inescapable preshock as determinants of response to punishment. Journal of Comparative and Physiological Psychologv, 1968, 65. (3, Part 2), 1-17.

BANKS, R. K. Intermittent punishment effect (IPE) sustained through changed stimulus conditions and through blocks of nonpunished trials. Journal of Experimental Psychology, 1967, 73, 456-460.

Brown, R. T., \& W WGNER, A. R. Resistance to punishment and extinction following training with shock or nonreinforcement. Journal of Experimental Psychology, 1964, 68, 503-507.

FALLON, D. Increased resistance to extinction following punishment and reward: High frustration tolerance or low frustration magnitude? Journal of Comparative and Physiological Psychology. 1971, 77. 245-255.

Glazer, H. 1., \& WEISS, J. M. Long-term and transitory interference effects. Journal of Experimental Psychology: Animal Behavior Processes, 1976, 2, 191-201. (a)
Glazer, H. I., \& Weiss, J. M. Long-term interference effect: An alternative to "learned helplessness." Journal of Experimental Psychology: Animal Behavior Processes, 1976, 2, 202-213. (b)

Goodrich, K. P. Performance in different segments of an instrumental response chain as a function of reinforcement schedule. Journal of Experimental Psychology, 1959, 57, 57-63.

HAGGARD, D. F. Acquisition of a simple running response as a function of partial and continuous schedules of reinforcement. Psychological Record, 1959, 9, 11-18.

Maier, S. F., Anderson, C., \& Lieberman, D. A. Influence of control of shock on subsequent shock-elicited aggression. Journal of Comparative and Physiological Psychology, 1972, 81, 94-100.

Maier, S. F., \& Seligman, M. E. P. Learned helplessness: Theory and evidence. Journal of Experimental Psychology: General. 1976, 105, 3-46.

Maier, S. F.. Seligman, M. E. P..\& Solomon, R. L. Pavlovian fear conditioning and learned helplessness. In B. A. Campbell \& R. M. Church (Eds.), Punishment. New York: AppletonCentury-Crofts, 1969.

Rosellini, R., \& Seligman, M. E. P. Learned helplessness and escape from the frustration. Journal of Experimental Psychology: Animal Behavior Processes, 1975, 1, 149-158.

Seligman, M. E. P., Maler, S. F., \& Solomon, R. L. Unpredictable and uncontrollable aversive events. In F. R. Brush (Ed.) Aversive conditioning and learning. New York: Academic Press, 1971.

TERRIS, W.,\& WEChKIN, S. Approach-avoidance conflict behavior as a function of prior experience with mild or intense electric shock stimulation. Psychonomic Science, 1967, 7, 169-170.

W AGNER, A. R. Frustration and punishment. In R. N. Haber (Ed.), Current research in motivation. New York: Holt, Rinehart. \& Winston, 1966.

Weiss, J. M., Glazer, H. I., \& Pohorecky, L. A. Coping behavior and neurochemical changes: An alternative explanation for the original "learned helplessness" experiments. In G. Serban \& A. Kling (Eds.), Animal models in human psychobiology. New York: Plenum Press, 1976.

Wong, P. T. P. Coerced approach to shock and resistance to punishment suppression and extinction in the rat. Journal of Comparative and Physiological Psychology, 1971, 75, 82-91.

(Received for publication February 16, 1977; revision accepted May $17,1977$. 